\title{
Analysis of Strength on Thick Plate Part using Genetic Algorithm Optimisation Method
}

\author{
S.M. Azlan ${ }^{1}$, Z. Shayfull ${ }^{1,2,{ }^{*}}$, S.M. Nasir ${ }^{1,2,3}$, Mohd Sazli Saad ${ }^{1,2}$, M.M. Rashidi ${ }^{4}$, and M. \\ Fathullah $^{1,2}$ \\ ${ }^{1}$ School of Manufacturing Engineering, Universiti Malaysia Perlis, Kampus Tetap Pauh Putra, 02600 \\ Arau, Perlis, Malaysia. \\ ${ }^{2}$ Green Design and Manufacture Research Group, Center of Excellence Geopolymer and Green \\ Technology (CEGeoGTech), Universiti Malaysia Perlis, 01000 Kangar, Perlis, Malaysia. \\ ${ }^{3}$ Centre For Diploma Studies, Universiti Malaysia Perlis, Malaysia. \\ ${ }^{4}$ Faculty of Mechanical Engineering, Universiti Malaysia Pahang, 26600 Pekan, Pahang, Malaysia.
}

\begin{abstract}
This study focuses on the optimisation of the injection moulding parameters to maximise the strength ofmoulded parts using a simulation software. The moulded parts were injected with AcrylonitrileButadiene-Styrene (ABS) whereas mould temperature, melt temperature, packing pressure and packing time were selected as variable process parameters. The polynomial model obtained using Design of Experiment (DOE) was integrated with the Response Surface Methodology (RSM) and Centre Composite Design (CCD). The RSM was supported with Genetic Algorithm (GA) to anticipate the optimum value of processing parameters with the highest strength. It was found that strength of the parts can be improved $2.2 \%$ using the methodology reported herein.
\end{abstract}

\section{Introduction}

Injection moulding is among the most important polymer processing methods to produce plastic parts [1]. There are several defects on moulded part that normally appear during the injection moulding process is taking place. Among the defects are warpage, shrinkage, and weld line which influence the cosmetic quality on the surface as well as on the strength of the part. Processing parameters such as melt temperature, mould temperature, packing pressure and packing time are the main factors affecting the quality of the plastic parts produced by the injection moulding process [2-7].

Based on literature reviews (which will be discussed below), many researches have studied to improve the warpage and shrinkage by utilising Genetic Algorithm optimisation method. Park and Nguyen [8] investigated the car fender-based moulded with materials fiber-reinforced plastic, Noryl GTX810 in injection moulding process. Response Surface Methodology and Non Dominated Sorting Genetic Algorithm II (NGSA II), the multiobject optimisation method was used to find optimal values of clamping force and warpage defect. The value of clamping force was reduced 10.7\% (from 4291 tonne to 3831 tonne)

\footnotetext{
*Corresponding author: shayfull@unimap.edu.my
} 
and warpage value was reduced also $10.7 \%$ (from $3.577 \mathrm{~mm}$ to $3.194 \mathrm{~mm}$ ). The results showed that the proposed method can be applied to optimise the processing parameters in solving the trade-off between consumption of energy (clamping force) and the quality of the product (warpage) produced.

Moreover, Kurtaran et al. [9] investigated on minimisation of warpage by optimising the processing parameters in injection moulding processes. A bus ceiling lamp base moulded by Acrylonitrile-Butadiene-Styrene (ABS) was used as a case study. Finite Element (FE) model of the lamp base was performed using a commercial software MoldFlow based on hybrid finite element. The injection time of $4.74 \mathrm{~s}$, injection pressure of $15 \mathrm{MPa}$, packing pressure of $60 \mathrm{MPa}$, packing time $8 \mathrm{~s}$ and cooling time are $15 \mathrm{~s}$ were set during analysis. The result showed that, the warpage of the bus ceiling lamp base was reduced to $46.5 \%$ after optimisation using Genetic Algorithm (GA).

Furthermore, Yoshiko et al. [10] investigated on improvement of mechanical properties moulded by green-composites based on Polylactic Acid TE-8000 (PLA) with jute fibers. A tensile test was conducted using a universal testing machine (Autograph AG-1, Shimadzu Co.) based on the Japanese Industrial Standard (JIS) K71. It was found that, the strength of PLA reduced from $49.8 \mathrm{MPa}$ to $28 \mathrm{MPa}$, but impact strength had increased more than $60 \%$ with the addition of the $50 \%$ of jute fiber.

Another investigation was made by Chen and Kurniawan [11] who optimised the processing parameters of multiple quality characteristics in the plastic part through two stage optimisation system. In the first stage optimisation, $\mathrm{S} / \mathrm{N}$ ratio and GA were used to reduce the variance of quality characteristic. In the second stage optimisation, the $\mathrm{S} / \mathrm{N}$ ratio with hybrid PSO-GA were used to find an optimal setting of processing parameter for quality characteristic and stability of the process. The specimens were moulded using Victor Taichung VS-80 injection moulding machine. The Mitutoyo digital slide caliper and a NV300T laser measurement machine were used to measure the length and warpage on the moulded parts. The processing parameters such as melt temperature, injection velocity, packing pressure, packing time and cooling time were selected as variable parameters. As a result, the proposed optimisation system successfully found that the optimal parameters setting to obtain the dimensions as per designed and reducing warpage $48.5 \%$ (from 0.198 $\mathrm{mm}$ to $0.096 \mathrm{~mm}$ ).

GA solves the optimisation problem by using simulating the biological evolution process, Darwin's theory of survival of the fittest [14]. The solution starts with a set of potential solution that refers as population or chromosomes. Chromosomes are in the form of bit strings and are generated randomly. The chromosomes evolve during a several generations and the generation correspond to the optimisation iteration. New generation has generated by using the mutation and crossover technique. The crossover involves splitting two chromosomes and then combining one-half of each chromosome with the other pair and mutation involves flipping a single bit of a chromosome. The chromosome has evaluated using a certain fitness criteria. This process in GA was repeated until the best fitness of chromosome had been chosen. In this study, the population size of 50, crossover rate of 1.0 , mutation rate of 0.1 , bit number for 4 variables of 19 except for packing time is 17 and the numbers of generations of 100 are employed. Therefore the practises of trial and error method can be reduced in order to find an optimal setting of processing parameters. At the same time the material and labour cost and time were used for mould testing to obtain the mechanical strength required by the customers can be reduced.

In this study, an experimental work was conducted to determine and to assist the injection moulding industries in order to gain an optimal setting of processing parameters with the highest strength of the moulded parts. In the beginning, Response Surface Methodology (RSM) was used to obtain the metahematical model. RSM is an empirical 
modelling approach used to determine the relationship between various processing parameters and responses with the various desired criteria and searches for the significance of these processing parameters in the coupled responses [12]. It is a sequential experimentation strategy to build and optimise an empirical model. Therefore, RSM is a collection of mathematical and statistical procedures which can be used for modelling and analysis the problems where the desired response is affected by several variables. The mathematical model of the desired response to the several independent input variables was gained using the experimental design and applying the regression analysis [13]. The mathematical model obtained from RSM was then used in GA to solve an optimisation problem in order to find the highest strength of the thick plate parts.

\section{Methodology}

This study focused on the strength effect based on a specified ranges of parameters set. The tests were conducted using Genetic Algorithm method towards the tensile strength of plastic part which conducted experimentally to obtain an optimal setting of processing parameters and maximum tensile strength. There are a few factors that influence the mechanical strength of plastic product produced from injection moulding process such as shape of product, plastic material, types of material for mould inserts, injection moulding machine, processing parameters, cooling channels design, types of coolant and room temperature [15].

This study can be divided into three phases which are selection of part design used, simulation the flow of the selected plastic material into mould cavities using Autodesk Moldflow Insight 2012 (AMI) and then experimental works using injection moulding machine and conducting tensile testing using Universal Testing Machine (UTM). Based on the simulation results, the set of parameters as shown in Table 1 had been obtained from Fill, Fill + pack and Cool (FEM) analyses were used to generated two-level full factorial design and will be analysed using Design of Experiment (DOE) to obtain the parameters setting before optimisation.

Table 1. Summarise results from AMI 2012 analysis

\begin{tabular}{|l|c|}
\hline Parameter Setting & Value \\
\hline Melt temperature $\left({ }^{\circ} \mathrm{C}\right)$ & 245 \\
\hline Mould temperature $\left({ }^{\circ} \mathrm{C}\right)$ & 65 \\
\hline Fill time $(\mathrm{s})$ & 2.75 \\
\hline Packing time $(\mathrm{s})$ & 12.3 \\
\hline Packing Pressure $(\mathrm{MPa})$ & 50 \\
\hline Cooling time $(\mathrm{s})$ & 15.7 \\
\hline Coolant inlet temperature $\left({ }^{\circ} \mathrm{C}\right)$ & 50 \\
\hline
\end{tabular}

The design of thick plate part with the dimensions of $152 \mathrm{~mm}$ x $20 \mathrm{~mm} \times 4 \mathrm{~mm}$ and the fabricated mould are shown in Figure 1 and 2, respectively. The thick plate parts were moulded using ABS material using 80 Tonnage injection moulding machine, NEX1000 as shown in Figure 3. Table 2 shows the technical specifications for the injection moulding machine used in this study. 


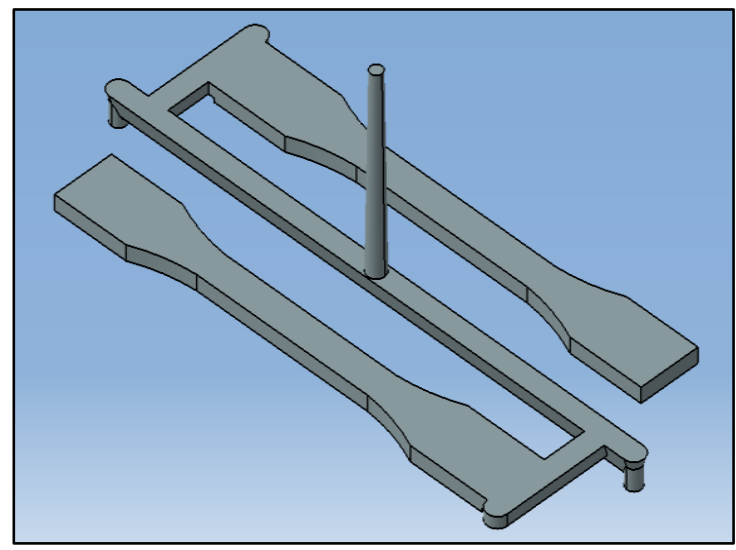

Fig. 1. Thick plate part with gating system.

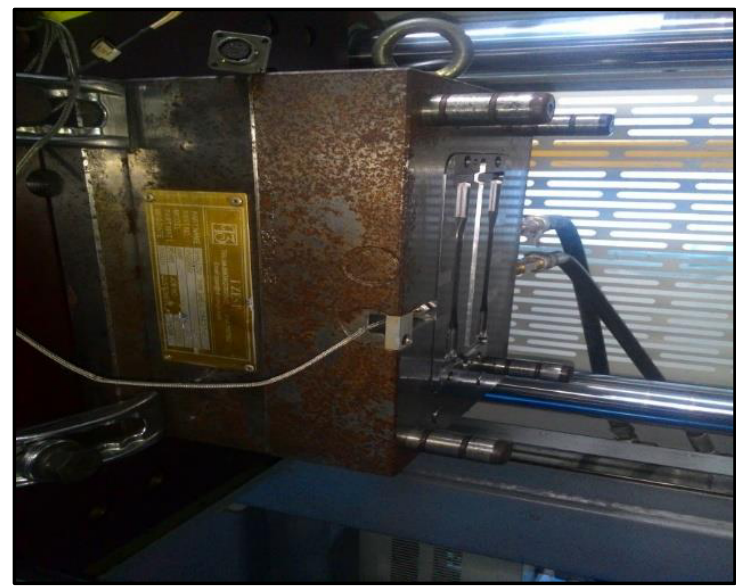

Fig. 2. An injection mould for thick plate part specimen.

Table 2. Technical specifications for injection moulding machine, Nissei NEX1000.

\begin{tabular}{|c|c|c|}
\hline \multirow{3}{*}{} & Screw diameter, $\mathrm{mm}$ & 28 \\
\cline { 2 - 3 } & Injection capacity, $\mathrm{cm}^{3}$ & 69 \\
\cline { 2 - 3 } & Plasticising capacity, $\mathrm{kg} / \mathrm{hr}$ & 28 \\
\cline { 2 - 3 } & Injection pressure, $\mathrm{MPa}$ & 243 \\
\cline { 2 - 3 } & Packing pressure, $\mathrm{MPa}$ & 205 \\
\hline \multirow{3}{*}{} & Clamping force, $\mathrm{tf}$ & 80 \\
\cline { 2 - 3 } & Clamping stroke, $\mathrm{mm}$ & 300 \\
\cline { 2 - 3 } & Mould thickness, $\mathrm{mm}$ & $200-385$ \\
\cline { 2 - 3 } & Ejector force, $\mathrm{tf}$ & 2 \\
\cline { 2 - 3 } & Ejector troke, $\mathrm{mm}$ & 8.36 \\
\hline \multirow{3}{*}{} & Heating capacity, $\mathrm{kW}$ & $4.19 \times 1.12 \times 68$ \\
\cline { 2 - 3 } & $\begin{array}{c}\text { Machine dimensions } \\
\text { (L x W x H), } \mathrm{m}\end{array}$ & 3.7 \\
\cline { 2 - 3 } & \multirow{2}{*}{\begin{tabular}{c} 
Machine weight, tonne \\
\cline { 2 - 3 }
\end{tabular}} & \\
\hline
\end{tabular}




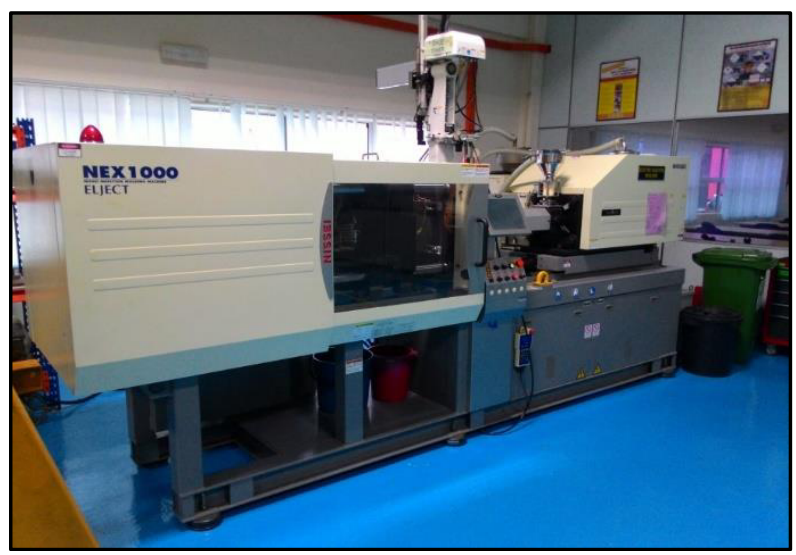

Fig. 3. Injection Moulding Machine, Nissei NEX1000.

\subsection{Thermoplastic material}

ABS material, Poyolac manufactured by Chi Mei Corporation has been used as a thermoplastic material in this study. The properties of plastic and mould material are shown in Table 3.

Table 3. Material properties of the plastic resin.

\begin{tabular}{|l|c|}
\hline Plastic material & ABS \\
\hline Trade name/Grade & Polylac PA-777B \\
\hline Supplier & Chi Mei Corporation \\
\hline Mould shrinkage (ASTM D638) & $0.4-0.6 \%$ \\
\hline No flow melt temperature $\left({ }^{\circ} \mathrm{C}\right)$ & 132 \\
\hline Minimum melt temperature $\left({ }^{\circ} \mathrm{C}\right)$ & 220 \\
\hline Maximum melt temperature $\left({ }^{\circ} \mathrm{C}\right)$ & 270 \\
\hline Minimum mould temperature $\left({ }^{\circ} \mathrm{C}\right)$ & 40 \\
\hline Maximum mould temperature $\left({ }^{\circ} \mathrm{C}\right)$ & 90 \\
\hline
\end{tabular}

\subsection{Design of experiment (DOE)}

In this study, two-level full factorial designs with four factors was selected as an experimental design using Design Expert 7.0 software. The factorial design was conducted to observe the significant of curvature while the second order model will propose should the curvature is significant. All variable parameters such as mould temperature, melt temperature, packing pressure and packing time are independent factors considered in this study. Table 4 shows the levels for each variable factor. 
Table 4. Factors and levels for DOE

\begin{tabular}{|c|c|c|}
\hline \multirow{2}{*}{ Factors } & \multicolumn{2}{|c|}{ Level } \\
\cline { 2 - 3 } & Minimum & Maximum \\
\hline Mould temperature, $\mathrm{A}\left({ }^{\circ} \mathrm{C}\right)$ & 40 & 90 \\
\hline Melt temperature, $\mathrm{B}\left({ }^{\circ} \mathrm{C}\right)$ & 220 & 270 \\
\hline Packing pressure, $\mathrm{C}(\mathrm{MPa})$ & 30 & 70 \\
\hline Cooling time, $\mathrm{D}(\mathrm{s})$ & 7.3 & 17.3 \\
\hline
\end{tabular}

\subsection{Responses surface methodology}

The parameters setting in this study was generated using the specified conditions according to the rotatable Centred Composite Design (CCD) in obtaining the maximum strength from the moulded structure. The parameters of the experiment in this study are shown in Table 5. The curvature is significant, thus the factorial design is augmented to CCD with alpha, $\alpha$ value is 0.05 to an adequate quadratic model of the RSM. The empirical model in this study was obtained using the quadratic model or also known as the secondorder polynomial regression model. The necessary information to construct the response model are generally accumulated by the value obtained from simulation works such as mould temperature $\left({ }^{\circ} \mathrm{C}\right)$, melt temperature $\left({ }^{\circ} \mathrm{C}\right)$, packing pressure $(\mathrm{MPa})$ and packing time (s). The factorial portion of CCD is a full factorial design with all combinations of the genes at two levels (high, +1 and lower, -1) and collected of the eight axial points and six central points (coded level 0 ) which is the midpoint between the high and low points. 
Table 5. Parameters setting in DOE

\begin{tabular}{|c|c|c|c|c|}
\hline \multirow[b]{2}{*}{ Run } & \multicolumn{4}{|c|}{ Setting parameters for injection moulding simulation } \\
\hline & 흘 & 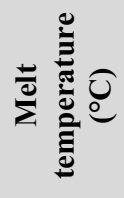 & 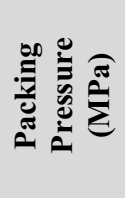 & 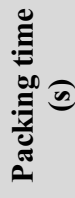 \\
\hline 1 & 90 & 270 & 30 & 17.3 \\
\hline 2 & 40 & 270 & 70 & 7.3 \\
\hline 3 & 65 & 245 & 50 & 12.3 \\
\hline 4 & 65 & 245 & 50 & 12.3 \\
\hline 5 & 90 & 270 & 70 & 17.3 \\
\hline 6 & 40 & 220 & 30 & 17.3 \\
\hline$\underline{7}$ & $\underline{90}$ & 270 & $\underline{30}$ & 7.3 \\
\hline 8 & 90 & 220 & $\overline{70}$ & $\overline{7.3}$ \\
\hline 9 & 40 & 270 & 70 & 17.3 \\
\hline 10 & 65 & 245 & 50 & 12.3 \\
\hline 11 & 90 & 270 & 70 & 7.3 \\
\hline 12 & 40 & 220 & 70 & 17.3 \\
\hline 13 & 90 & 220 & 70 & 17.3 \\
\hline 14 & 40 & 220 & 30 & 7.3 \\
\hline 15 & 90 & 220 & 30 & 7.3 \\
\hline 16 & 90 & 220 & 30 & 17.3 \\
\hline 17 & 40 & 220 & 70 & 7.3 \\
\hline 18 & 40 & 270 & 30 & 17.3 \\
\hline 19 & 40 & 270 & 30 & 7.3 \\
\hline 20 & 65 & 245 & 50 & 12.3 \\
\hline 21 & 65 & 245 & 30 & 12.3 \\
\hline 22 & 65 & 270 & 50 & 12.3 \\
\hline 23 & 65 & 245 & 50 & 17.3 \\
\hline 24 & 65 & 245 & 50 & 12.3 \\
\hline 25 & 65 & 245 & 50 & 7.3 \\
\hline 26 & 65 & 220 & 50 & 12.3 \\
\hline 27 & 65 & 245 & 70 & 12.3 \\
\hline 28 & 90 & 245 & 50 & 12.3 \\
\hline 29 & 40 & 245 & 50 & 12.3 \\
\hline 30 & 65 & 245 & 50 & 12.3 \\
\hline
\end{tabular}

\section{Result and Discussion}

Based on the analysis was conducted using Response Surface Methodology (RSM), the results of Analysis of Variance (ANOVA) are shows in Table 6. It can be seen that, the melt temperature is the most significant factors that affected to the strength of the moulded parts. This result in line with Ozcelik et al. [16] which found that the melt temperature and packing pressure have the greatest effect on the weld line and the tensile strength of the moulded parts. This statement also agreed by Mathiavanan \& Parthasaraty [17] which reported that melt temperature and packing pressure is the most influence on the strength of the moulded parts. In addition, Gou et al. [18] also reported that melt temperature has a significant effect on strength of the moulded parts. 
Table 6. ANOVA results from DOE

\begin{tabular}{|c|c|c|c|c|c|c|}
\hline : & 忒 & 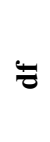 & $\sum_{\Sigma}^{E}$ & 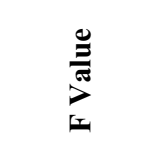 & 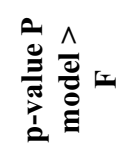 & \\
\hline Block & 6.68 & 1 & 6.68 & & & \\
\hline Model & 10.82 & 7 & 1.55 & 11.77 & $<0.0001$ & 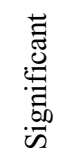 \\
\hline B-Melt temperature & 6.15 & 1 & 6.15 & 46.85 & $<0.0001$ & \\
\hline C-Packing Pressure & 0.66 & 1 & 0.66 & 5.04 & 0.0357 & \\
\hline D- Packing Time & $3.423 \times 10^{-6}$ & 1 & $3.423 \times 10^{-6}$ & $2.606 \times 5 \times 10$ & 0.9960 & \\
\hline $\mathrm{BD}$ & 0.76 & 1 & 0.76 & 5.80 & 0.0253 & \\
\hline $\mathrm{CD}$ & 1.88 & 1 & 1.88 & 14.28 & 0.0011 & \\
\hline $\mathrm{B}^{2}$ & 0.61 & 1 & 0.61 & 4.65 & 0.0427 & \\
\hline $\mathrm{D}^{2}$ & 1.36 & 1 & 1.36 & 10.32 & 0.0042 & \\
\hline Residual & 2.76 & $\begin{array}{l}2 \\
1\end{array}$ & 0.13 & & & \\
\hline Lack of fit & 2.76 & $\begin{array}{l}1 \\
7\end{array}$ & 0.16 & 197.60 & $<0.0001$ & 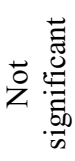 \\
\hline Pure error & $\begin{array}{l}3.281 \\
\times 10^{-3} \\
\end{array}$ & 4 & $8.201 \times 10^{-4}$ & & & \\
\hline Cor total & 20.27 & $\begin{array}{l}2 \\
9\end{array}$ & & & & \\
\hline
\end{tabular}

Based on the parameter setting generated by DOE in Table 5, it can be seen that the parameter setting of run number 24 is identical with the parameters setting used in simulation works as shown in Table 1. The value of the ultimate tensile strength of the run number 24 is $38.4626 \mathrm{MPa}$ as shown in Table 7. Therefore, the value of tensile strength of run number 24 (before optimization) was used to compare the tensile strength obtained after the optimization took place. In this study, a mathematical model was obtained for the use in the MATLAB software by using Design Expert software and RSM in order to maximise the tensile strength on the moulded parts produced with an optimal setting of processing parameters. The mathematical model obtained is shown in Equation 1 below:

$$
\begin{array}{rl}
\text { Strength }=75 & 49189-(0.34642 \times B)+(0.051703 C)+(1.24240 D) \\
& -\left(1.74507 \times 10^{-3} \times B C\right)-\left(3.42434 \times 10^{-3} \times B D\right) \\
& +\left(7.03051 \times 10^{-4} \times B^{2}\right)-\left(0.026168 \times D^{2}\right.
\end{array}
$$

Where A is mould temperature $\left({ }^{\circ} \mathrm{C}\right), \mathrm{B}$ is melt temperature $\left({ }^{\circ} \mathrm{C}\right), \mathrm{C}$ is packing pressure $(\mathrm{MPa})$ and $\mathrm{D}$ is packing time (s). The ranges of $\mathrm{A}, \mathrm{B}, \mathrm{C}$ and $\mathrm{D}$ were selected based on the 
recommended values obtained from simulation works using Autodesk Moldflow Indisght (AMI) 2012 as shown in Table 4.

Table 7. Summary results of Ultimate Tensile Strength for thick plate part.

\begin{tabular}{|c|c|}
\hline Run & Ultimate Tensile Strength, $\sigma_{\mathrm{uts}}(\mathrm{MPa})$ \\
\hline 1 & 39.1373 \\
\hline 2 & 40.0161 \\
\hline 3 & 40.0576 \\
\hline 4 & 40.0576 \\
\hline 5 & 38.5548 \\
\hline 6 & 40.0100 \\
\hline 7 & 38.5973 \\
\hline 8 & 40.5696 \\
\hline 9 & 38.4682 \\
\hline 10 & 40.0576 \\
\hline 11 & 40.4294 \\
\hline 12 & 40.4855 \\
\hline 13 & 40.2298 \\
\hline 14 & 39.8732 \\
\hline 15 & 39.7466 \\
\hline 16 & 40.2719 \\
\hline 17 & 40.2022 \\
\hline 18 & 39.1512 \\
\hline 19 & 38.3533 \\
\hline 20 & 40.0576 \\
\hline 21 & 38.9426 \\
\hline 22 & 38.9745 \\
\hline 23 & 38.7382 \\
\hline 24 & 38.4626 \\
\hline 25 & 38.0670 \\
\hline 26 & 40.0179 \\
\hline 27 & 38.5780 \\
\hline 28 & 38.8477 \\
\hline 29 & 38.5396 \\
\hline 30 & 38.3816 \\
\hline
\end{tabular}

\subsection{Optimisation through Genetic Algorithm}

In this study, Genetic Algorithm (GA) method was used to optimise the processing parameters to mould a thick plate parts with the highest tensile strength. The equation (from RSM) was written in MATLAB programming language as shown in Equation 2 based on the Analysis of variance (ANOVA) model to solve the optimisation problem. The 
maximum strength is defined in the standard optimisation problem format that can be solved by a numerical optimisation algorithm. Standard optimisation problem definition requires an objective function to be minimised or maximised and constraint functions to be satisfied in terms of optimisation parameters. For a thick plate part model, an optimisation problem can be defined as follows:

To find: $\quad$ A, B, C, D

To maximise: Strength (A, B, C, D)

Within parameter ranges:

$$
\begin{gathered}
40^{\circ} \mathrm{C} \leq \mathrm{A} \leq 90^{\circ} \mathrm{C} \\
220^{\circ} \mathrm{C} \leq \mathrm{B} \leq 270^{\circ} \mathrm{C} \\
30 \mathrm{MPa} \leq \mathrm{C} \leq 70 \mathrm{MPa} \\
7.3 \mathrm{~s} \leq \mathrm{D} \leq 17.3 \mathrm{~s}
\end{gathered}
$$

\begin{tabular}{|c|c|c|c|}
\hline & & $\begin{array}{c}\text { Before } \\
\text { Optimisation }\end{array}$ & $\begin{array}{c}\text { After } \\
\text { optimisation }\end{array}$ \\
\hline \multirow{5}{*}{ 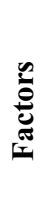 } & Mould temperature, ${ }^{\circ} \mathrm{C}$ & 65 & 51.8521 \\
\hline & Melt temperature, ${ }^{\circ} \mathrm{C}$ & 270 & 248.0365 \\
\hline & Packing pressure, MPa & 30 & 31.5412 \\
\hline & Packing time, $\mathrm{s}$ & 12.3 & 7.3212 \\
\hline & $\begin{array}{l}\text { Ultimate Tensile Strength, } \\
\mathrm{MPa}\end{array}$ & 38.4626 & 39.3063 \\
\hline
\end{tabular}

Table 8. Comparision of processing parameters setting before and after optimisation

The results in Table 8 shows that the values of the UTS increased from 38.4626 to 39.3063. In other words, the maximum strength on the thick plate parts improved approximately $2.2 \%$ after the optimisation using GA method and the iterations of the optimisation history was demonstrated in Figure 4.

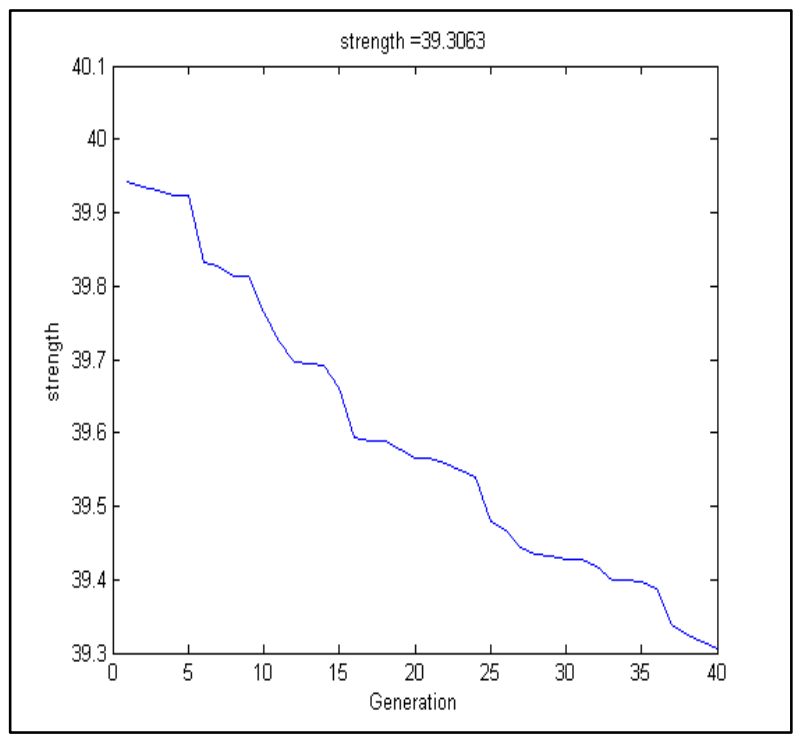

Fig. 4. The values of strength was obtained in MATHLAB software. 


\section{Conclusion}

An efficient optimisation method using GA and RSM was useed to estimate an optimal solution of injection moulding process in order to maximise the strength on the thick plate part. The mathematical model of the strength has been carried out to correlate the dominant of the injection moulding parameters of the mould the thick plate part using ABS material. To obtain the maximum strength, the appropriate process condition parameters were determined based on the significant factor results as shown in Table 4. Mould temperature, melt temperature, packing pressure and packing time were considered as a variable processing parameters. The anaylses showed that the strength of the thick plate part can improve $2.2 \%$ after the optimisation. An optimal solution has been predicted based on a polynomial model created using RSM with CCD. This indicates that an optimisation method used in this study can be employed to improve the strength of the moulded parts required the strength for fuctionality.

\section{References}

1. E. Sachs, E. Wylonis, S. Allen, M. Cima, H. Guo, Polym. Eng. Sci., 40, 5 (2000)

2. A.I. Isayav, Injection and Compression Molding (Marcel Dekker, New York, 1987)

3. G.U. Yuanxian, L.I. Haimei, S. Changyo, Adv. Polym. Technol, 20, 1 (2001)

4. T.J. Wang, C.K. Yoon, SPE ANTEC Proceedings, 1, 687 (2000)

5. S.J. Lui, Polym. Eng. Sci., 3, 5 (1995)

6. B.H. Lee, B.H. Kim, Polym. Plast. Technol. Eng., 34, 5 (1995)

7. H. Ming Chih, T. Ching-Chih, Process. Technol., 1, 10 (2001)

8. H.S. Park, T.T. Nguyen, J. Comput. Des. Eng., 1, 4 (2014)

9. H. Kurtaran, B. Ozcelik, T. Erzurumlu, J. Mater. Process. Tech., 169, 314 (2005)

10. Y. Arao, T. Fujiura, S. Itani, T. Tanaka, Compos. Part B Eng., 68, 1 (2015)

11. W. Chen, D. Kurniawan, Int. J. Precis. Eng. Manuf., 15, 1583 (2014)

12. R.H. Myers, D.C. Montgomery, Response Surface Methodology: Process and Product Optimization Using Designed Experiments (Wiley, New York, 1995)

13. D.C. Montgomery, Design and Analysis of Experiments (Wiley, New York, 2001)

14. D.E. Goldberg, Genetic Algorithms in Search, Optimization and Machine Learning (Addison-Wesley, Boston, 1989)

15. Z. Shayfull, M. Fathullah, S.M. Nasir, N.A. Shuib, M.S. Abdul Manan, International Review of Mechanical Engineering, 6, 1 (2012)

16. B. Ozcelik, E. Kuram, M. M. Topal, Int. Commun. Heat Mass Transf., 39,2 (2012)

17. D. Mathivanan, N. S. Parthasarathy, Int. J. Adv. Manuf. Technol., 43, 654 (2009)

18. W. Guo, L. Hua, H. Mao, 3, 4 (2014) 